\title{
Ceruletide increases dose dependently both jejunal motor activity and threshold and tolerance to experimentally induced pain in healthy man
}

\author{
G STACHER, H STEINRINGER, G SCHMIERER, C SCHNEIDER, \\ $S$ WINKLEHNER, G MITTELBACH, C DE PAOLIS, AND C PRAGA
}

From the Psychophysiology Unit at the Psychiatric and First Surgical Clinic, University of Vienna, Vienna, Austria, and Farmitalia Carlo Erba, Milano, Italy

SUMMARY The effects of ceruletide on jejunal motility and experimentally induced pain were studied in 16 healthy men, who participated each in four experiments and received in random double blind fashion 5, 10, or $20 \mu \mathrm{g}$ ceruletide intramuscularly or placebo. Jejunal pressures were recorded by three perfused catheters with orifices between 10 and $20 \mathrm{~cm}$ aboral of the ligament of Treitz. Ceruletide dose dependently diminished phase I and increased phase II type activity and tended to reduce the number, but not the duration, of activity fronts. The number and amplitude of contractions as well as the area under the curve increased significantly and dose dependently as did threshold and tolerance to electrically and threshold to thermally induced pain. Only mild sedative and other side effects occurred.

Ceruletide (INN proposed by the WHO) or, as it was named formerly, caerulein is a decapeptide of the amino acid sequence Pyr-Gln-Asp-Tyr $\left(\mathrm{SO}_{3} \mathrm{H}\right)$ Thr-Gly-Trp-Met-Asp-Phe- $\mathrm{NH}_{2}$ and is structurally related to the cholecystokinin (CCK) - gastrin family. It was isolated from the skin of the Australian hylid frog Hyla caerulea by the group of Erspamer $^{1}$ and synthesised subsequently. ${ }^{2}$ The peptide has been reported to stimulate myoelectrical spiking as well as the contractile activity of the distal duodenum and the jejunum in $\operatorname{man}^{34}$ and, in the rat, ${ }^{5}$ to increase the tone of all segments of the small intestine except of the duodenum, and to reduce the transit time strikingly not only in healthy subjects but also in patients suffering from postoperative intestinal paralysis. ${ }^{6-10}$ These actions of ceruletide parallel those of its mammalian counterpart cholecystokinin which has been shown to increase dose relatedly the motor activity of the jejunum ${ }^{11-13}$ and to increase jejunal but not duodenal and ileal spike activity. ${ }^{14}$ It has been discovered recently that these peptides not only have potent effects on the gastrointestinal tract but also are endowed with analgesic properties: in mice ceruletide and cholecystokinin

Address for correspondence: Dr G Stacher. Psychophysiologisches Laboratorium. Psychiatrische Universitätsklinik. Währinger Gürtel 74-76. A-1090 Wien, Austria.

Received for publication 12 August 1983 produce a decrement in response to noxious stimulation, ${ }^{1516}$ in man ceruletide yields prompt and complete relief of pain not only from biliary ${ }^{17-19}$ but also from renal colics, ${ }^{17}$ abolishes cancer pain,${ }^{20}$ and alleviates experimentally induced pain. ${ }^{21} 22$ The present study was performed to investigate whether synthetic ceruletide (Farmitalia Carlo Erba, Milan, Italy; purity $94.8 \%$ ) in doses of 5,10 , and $20 \mu \mathrm{g}$ intramuscularly would exert both stimulating effects on the motor activity of the upper jejunum and analgesic effects on experimentally induced pain in healthy human subjects.

\section{Methods}

\section{SUBJECTS}

Sixteen healthy men ranging in age from 20 to 32 years (mean 25.4 years) were studied. Only subjects not taking drugs at the time of the experiment, having regular bowel movements, and without any history of gastrointestinal disease or previous abdominal surgery were included. They were given a short explanation of the purpose of the research and a description of the procedures to be followed. They were further given a description of any reasonably foreseeable risks or discomforts. Written consent to participate was obtained from each subject. Before it was initiated, the investigation 
was approved by the Institutional Committee on Studies Involving Human Subjects.

\section{EXPERIMENTAL DESIGN}

Each subject participated in four experimental sessions at one week intervals. The subjects were instructed to refrain from eating after 2200 hours on the evening preceding the experiment, and to eat and drink nothing before coming to the laboratory on the experimental day. A multilumen polyvinyl tube with recording orifices $3 \mathrm{~cm}$ apart and an empty rubber bag attached to its tip was inserted via the nose into the stomach. The bag was then filled with $2 \mathrm{ml}$ of mercury to facilitate transit. The tube was positioned under fluoroscopic control so that the pressure recording orifices were located between 10 and $20 \mathrm{~cm}$ aboral of the ligament of Treitz. After this procedure, the subjects reclined on a bed in a semirecumbent supine position and remained thus until the end of the experiment. Ten minutes after reclining the recording started. Each experiment comprised 1015 minute periods. The procedure during these periods was identical: from minute 1 to 5 , threshold and tolerance to electrically induced pain, threshold to thermally induced pain, reaction time to acoustic stimuli, and blood pressure were measured and the subjects asked to complete self-rating scales. During minute 6 to 15 , the subjects were instructed to refrain from speaking and from all unnecessary movements. At the beginning of the third 15 minute period, the subjects received, under double blind conditions, intramuscular injections of either (1) $5 \mu \mathrm{g}$ ceruletide, (2) $10 \mu \mathrm{g}$ ceruletide, (3) $20 \mu \mathrm{g}$ ceruletide or (4) saline placebo $(0 \cdot 15 \mathrm{M})$. The sequence in which they received the treatments on the different days was randomised according to a plan with four $4 \times 4$ Latin squares.

\section{Measurement of jejunal motor activity}

Jejunal pressures were recorded continuously by means of a multilumen catheter assembly and three orifices spaced at $3 \mathrm{~cm}$ intervals (Mui Scientific, Mississauga, Ontario, Canada). The catheters were perfused with distilled water by means of a pressurised capillary hydraulic infusion system (Mui Scientific) at 70 kilopascal (525 millimetres of mercury $(\mathrm{mmHg}))$. Pressures were transmitted to Beckman Type 4-327C transducers (Beckman Instruments, Inc, Schiller Park, Ill). The compliance of the entire recording system was such that a sudden occlusion of the perfused catheters produced a pressure rise of at least $100 \mathrm{mmHg}$ per second. The output of the transducers was recorded on a Beckman R-411 Dynograph using Beckman 9853A couplers. The amplified signals then were digitised on-line at 30 hertz $(\mathrm{Hz})$ by means of a HewlettPackard 21MX E-series computer (Hewlett-Packard Company, Palo Alto, Ca). Jejunal pressures were analysed by a computer program which determined for each one minute period the mean end-expiratory base line pressure, the number, the amplitude, and the duration of contractions, as well as the area enclosed by the pressure curve and the base line pressure as an overall index of motility. The pattern of jejunal motor activity was analysed blindly by two independent observers being unaware of the treatment given. The identification of an activity front or phase III of the fasting pattern of the migrating motor complex (MMC; 2324 ) was based on three criteria: the appearance of an uninterrupted burst of pressure waves of at least three minutes duration and produced at the slow wave frequency of the upper jejunum, the aboral progression of the front over all three recording orifices, and a period of complete quiescence following the activity front. The recordings of motility in the remaining time were divided into phase I, complete quiescence of at least three minutes duration subsequent to an activity front and recorded at all three catheter orifices, and phase II, intermittent activity.

\section{Respiratory rate, heart rate, and blood pressure}

Respiratory rate was monitored by means of a Beckman strain gauge pneumograph fitted around the subject's abdomen and a Beckman 9853A coupler, and heart rate was processed by a Beckman 9857 cardiotachometer coupler on the base of a chest wall electrocardiogram. Systolic and diastolic blood pressure were recorded by means of an automatic device (Boso-Digimat, Bosch \& Sohn, Jungingen, West Germany) and an inflatable cuff around the non-dominant arm.

Threshold and tolerance to electrically induced pain Chains of square wave constant current impulses of 1 millisecond duration and a pulse frequency of 30 $\mathrm{Hz}$ were used to induce pain. ${ }^{25-27}$ The intensity of the impulses increased, in steps of 0.05 milliampère, linearly from zero to 12.8 milliampère, the maximum intensity being reached within 25.6 seconds. The stimuli were administered by means of a pair of silver ball electrodes attached to the earlobe of the subjects' non-dominant side. The subjects were given a handle fitted with two push buttons and instructed to press the left button as soon as they perceived the stimuli as painful and thereby to indicate pain threshold, and to press the right button when they felt they could not tolerate any further increase of stimulus intensity and thereby to indicate pain tolerance. Pressing the second button stopped the stimulation. Six chains of stimuli were pre- 
sented. The interval between the chains ranged randomly from 15 to 25 seconds.

\section{Threshold to thermally induced pain}

Radiant heat of a constant intensity was used to induce pain. ${ }^{27} 28$ On the volar surface of the subjects' dominant forearm, six spots were marked and numbered from one to six. The subjects were required to press these spots sequentially against a switch mounted at an aperture, $6 \times 6 \mathrm{~mm}$ in size, on the stimulator. Without prior notice a projection filament lamp mounted within the stimulator was then turned on. The subjects were instructed to pull their forearm away from the aperture as soon as they perceived the radiant heat stimulus as painful and thereby to indicate their pain threshold. The time elapsing between the turning on of the lamp and the withdrawal of the arm, allowing the closure of the switch, was measured by a digital clock. The intervals between the applications of the stimuli ranged randomly from 15 to 25 seconds.

\section{Reaction time to acoustic stimuli}

Reaction time to acoustic stimuli was recorded in response to six tones presented with random intervals ranging from 10 to 20 seconds.

\section{Self-rating scales}

Visual analogue scales containing 14 pairs of polar adjectives, written on the right and the left edge of a sheet of paper, were used. Between the two words there was a $10 \mathrm{~cm}$ line and the subjects were instructed to mark that point of the line, which they considered to indicate most correctly their feelings in the given moment. Each three pairs of adjectives were aimed to obtain information on activation ('awake - drowsy', 'quick - slow', 'enterprising inert') and on wellbeing ('happy - unhappy', 'pleasant - unpleasant', 'oppressed - free'), while one pair ('warm - cold') was aimed to quantify feelings of warmth. The remaining pairs were non-relevant to the above dimensions. The mean ratings in each dimension were analysed.

\section{Side effects}

Side effects as reported spontaneously by the subjects were recorded together with the experimenters' observations.

\section{STATISTICAL ANALYSIS OF DATA}

An analysis of variance for repeated measures ${ }^{29}$ was performed on the differences between the mean values of each two consecutive 15 minute periods after drug administration (1-30, 31-60, 61-90, 91120 minutes) and the mean values of the two basal periods. The analysis investigated the influences of the fixed within subjects factors 'treatment' (one to four), 'day' (experimental days one to four), 'time' (periods 1-30, 31-60, 61-90, and 91-120 minutes after drug administration), as well as of the random factor 'subject' (one to 16). On the basis of the analysis of variance, linear and quadratic contrasts over the mean effects of the three doses of ceruletide were calculated to investigate dose response relationships, and a sequentially rejective multiple test procedure ${ }^{30}$ was used to evaluate differences between the treatment effects. In the latter procedure, an overall significance level of $\alpha=0.05$ was adopted.

\section{Results}

The analyses revealed that the factor 'day', that is the sequence in which the subjects received the four treatments in the different sessions, had no significant influence on their responses in any one measure.

\section{JEJUNAL MOTOR ACTIVITY}

\section{Pattern of motor activity}

After the administration of ceruletide, the percentage of motility recordings classified as phase I of the fasting pattern of the MMC decreased, whereas the percentage of tracings classified as phase II increased dose dependently (Table 1 ). The analysis showed that the treatment effects differed significantly (phase I: $F(3,168)=4.02, p<0 \cdot 01$; phase II: $F(3,168)=5.64, p<0.002)$, and that there were significant linear dose response relationships (phase I: $F(1,168)=9.43, p<0.005$; phase II : $\mathrm{F}(1,168)=14 \cdot 77, \mathrm{p}<0.001)$. Twenty micrograms ceruletide produced significantly larger shifts in phases I and II than did placebo and $5 \mu \mathrm{g}$ of the peptide. A total of 72 activity fronts (phase III) were observed in the 64 experimental sessions. Of these fronts, 27 occurred in the basal 30 and 45 minutes after drug administration. The number of activity fronts, but not their duration, tended to diminish with increasing dose of ceruletide (correlation coefficient, $r=0.904, p<0 \cdot 1$ ): 14 fronts with a mean duration of 7.4 min \pm 0.9 SEM were recorded after

Table 1 Percent distribution (mean $\pm S E M$ ) of phases I, II, and III of the fasting pattern of the migrating motor complex in the 120 min after drug administration

\begin{tabular}{lrrr}
\hline & Phase I & Phase II & Phase III \\
\hline Placebo & $18 \cdot 8 \pm 4 \cdot 7$ & $76 \cdot 1 \pm 4 \cdot 8$ & $5 \cdot 1 \pm 1 \cdot 0$ \\
$5 \mu$ g ceruletide & $19 \cdot 2 \pm 3 \cdot 0$ & $75 \cdot 6 \pm 3 \cdot 5$ & $5 \cdot 2 \pm 0 \cdot 8$ \\
$10 \mu$ g ceruletide & $14 \cdot 0 \pm 3 \cdot 4$ & $81 \cdot 2 \pm 4 \cdot 3$ & $4 \cdot 8 \pm 1 \cdot 2$ \\
$20 \mu$ g ceruletide & $4 \cdot 8 \pm 1 \cdot 9$ & $92 \cdot 1 \pm 2 \cdot 6$ & $3 \cdot 1 \pm 1 \cdot 0$ \\
\hline
\end{tabular}


the administration of $5 \mu \mathrm{g}$ ceruletide, 10 fronts with a mean duration of $7 \cdot 8 \pm 1.2$ minutes after $10 \mu \mathrm{g}$, and eight fronts with a mean duration of $9 \cdot 1 \pm 1 \cdot 4$ minutes after $20 \mu \mathrm{g}$ of the peptide, as compared with 13 activity fronts lasting $7 \cdot 9 \pm 0.7$ minutes after placebo.

\section{Number of contractions}

The number of jejunal contractions irrespective of the phases of the MMC increased dose dependently after administration of ceruletide, while it remained unchanged after placebo. With the two lower doses of ceruletide, the effects lasted for about 60 and 90 minutes, respectively, whereas with $20 \mu \mathrm{g}$ ceruletide the number of contractions was still raised 120 minutes after administration (Table 2). The analysis revealed significantly differing treatment effects $(F(3,168)=8.09, p<0.001)$ and a significant linear dose response relationship $(\mathrm{F}(1,168)=18 \cdot 26$, $\mathrm{p}<0.001)$. Twenty micrograms ceruletide produced significantly more contractions than each of the other treatments.

\section{Mean amplitude of contractions}

The mean amplitude increased dose dependently after ceruletide, whereas it decreased slightly after placebo. The effects of 5 and $10 \mu \mathrm{g}$ ceruletide lasted up to 90 minutes, while $20 \mu \mathrm{g}$ were still active after 120 minutes (Table 2). The treatment means differed significantly $(\mathrm{F}(3,168)=13.36, \mathrm{p}<0.001)$ and there was a significant linear dose response relationship $(F(1,168)=15 \cdot 42, p<0 \cdot 001)$. The effects of all doses of ceruletide differed significantly from placebo and $20 \mu \mathrm{g}$ of the peptide were significantly more active than 5 and $10 \mu \mathrm{g}$, respectively.

\section{Area under the curve}

This measure of overall contractile activity was increased markedly and in a dose related manner by ceruletide, while it was not altered by placebo (Table 2 ). The analysis revealed significantly differing treatment effects $(F(3,168)=9 \cdot 23$, $\mathrm{p}<0.001)$ and a linear dose response relationship $(\mathrm{F}(1,168)=17.68, \mathrm{p}<0 \cdot 001)$. Ten and $20 \mu \mathrm{g}$ ceruletide were significantly more active than placebo, and $20 \mu \mathrm{g}$ ceruletide more than 5 and $10 \mu \mathrm{g}$ of the peptide.

\section{Heart rate, blood pressure, and respiratory rate}

Heart rate, blood pressure, and respiratory rate were not altered systematically by any of the three doses of ceruletide.

\section{THRESHOLD TO ELECTRICALLY INDUCED PAIN}

Threshold increased after the administration of all doses of ceruletide, 5 and $10 \mu \mathrm{g}$ being about equally effective and $20 \mu \mathrm{g}$ having the strongest effect. Maximal effects were reached between 30 and 60 minutes, thereafter threshold levels remained high until the end of the experimental time. With placebo, only slight rises of threshold occurred (Table 3). The treatment effects differed significantly $(F(3,168)=11 \cdot 25, p<0 \cdot 001)$, and all doses of ceruletide were significantly more active than placebo. Twenty $\mu \mathrm{g}$ ceruletide were significantly superior in analgesic efficacy to 5 and $10 \mu \mathrm{g}$, whereas the actions of the latter two doses did not differ from each other. The investigation of dose response relationships revealed significant $F$ ratios for a linear $(F(1,168)=12.04, p<0 \cdot 001)$ but also for a quadratic relationship $(\mathrm{F}(1,168)=4.07, \mathrm{p}<0.05)$, reflecting the fact that the effects of the two lower ceruletide doses did not differ.

TOLERANCE TO ELECTRICALLY INDUCED PAIN All doses of ceruletide caused marked increases of

Table 2 Number of jejunal contractions per minute, mean amplitude of contractions, and area under the curve (mean \pm $S E M$ ) in the 30 minutes before (period 1) and in the four 30 minute periods after drug administration (periods 2 to 5)

\begin{tabular}{|c|c|c|c|c|c|c|}
\hline & \multirow[b]{2}{*}{ Treatment } & \multicolumn{5}{|l|}{ Period } \\
\hline & & 1 & 2 & 3 & 4 & 5 \\
\hline \multirow{4}{*}{$\begin{array}{l}\text { Number of contractions } \\
\text { per minute }\end{array}$} & Placebo & $2 \cdot 8 \pm 0 \cdot 2$ & $2 \cdot 7 \pm 0 \cdot 3$ & $2 \cdot 7 \pm 0 \cdot 3$ & $2 \cdot 9 \pm 0 \cdot 3$ & $2 \cdot 7 \pm 0 \cdot 3$ \\
\hline & $5 \mu \mathrm{g}$ ceruletide & $2 \cdot 8 \pm 0 \cdot 2$ & $3 \cdot 3 \pm 0 \cdot 3$ & $2 \cdot 9 \pm 0 \cdot 2$ & $2 \cdot 7 \pm 0 \cdot 3$ & $2 \cdot 4 \pm 0 \cdot 2$ \\
\hline & $10 \mu \mathrm{g}$ ceruletide & $2 \cdot 6 \pm 0 \cdot 3$ & $3 \cdot 1 \pm 0 \cdot 2$ & $3 \cdot 0 \pm 0 \cdot 3$ & $2 \cdot 5 \pm 0 \cdot 3$ & $2 \cdot 4 \pm 0 \cdot 3$ \\
\hline & $20 \mu \mathrm{g}$ ceruletide & $2 \cdot 3 \pm(0 \cdot 3$ & $3 \cdot 1 \pm 0 \cdot 2$ & $3 \cdot 5 \pm 0 \cdot 3$ & $2 \cdot 9 \pm 0 \cdot 3$ & $2 \cdot 7 \pm 0 \cdot 2$ \\
\hline \multirow[t]{4}{*}{ Mean amplitude $(\mathrm{mmHg})$} & Placebo & $8 \cdot 5 \pm 0 \cdot 7$ & $7 \cdot 1 \pm 1 \cdot()$ & $6 \cdot 9 \pm 0 \cdot 8$ & $7 \cdot 7 \pm 0 \cdot 8$ & $7 \cdot 1 \pm 0 \cdot 8$ \\
\hline & $5 \mu \mathrm{g}$ ceruletide & $8 \cdot() \pm 0 \cdot 8$ & $9 \cdot 4 \pm 1 \cdot 0$ & $8 \cdot 1 \pm 0 \cdot 7$ & $7 \cdot 5 \pm 0 \cdot 8$ & $6 \cdot 9 \pm 0 \cdot 7$ \\
\hline & $10 \mu \mathrm{g}$ ceruletide & $7 \cdot 7 \pm 0 \cdot 6$ & $9 \cdot 1 \pm(1) \cdot 7$ & $8 \cdot 8 \pm 0 \cdot 6$ & $7 \cdot 3 \pm 0 \cdot 8$ & $7 \cdot 1 \pm 0 \cdot 7$ \\
\hline & $20 \mu \mathrm{g}$ ceruletide & $7 \cdot 2 \pm 0 \cdot 8$ & $9 \cdot 5 \pm 1 \cdot 1$ & $10 \cdot 3 \pm 0 \cdot 9$ & $8 \cdot 9 \pm 0 \cdot 8$ & $7 \cdot 6 \pm 0 \cdot 5$ \\
\hline \multirow[t]{4}{*}{ Area under the curve } & Placebo & $6506 \pm 719$ & $5915 \pm 1009$ & $5754 \pm 1031$ & $6783 \pm 1045$ & $5793 \pm 986$ \\
\hline & $5 \mu \mathrm{g}$ ceruletide & $7370 \pm 994$ & $9250 \pm 1248$ & $77+4 \pm 1019$ & $6794 \pm 957$ & $5897 \pm 900$ \\
\hline & $10 \mu \mathrm{g}$ ceruletide & $61+4 \pm 822$ & $8985 \pm 1059$ & $82+1 \pm 1007$ & $6524 \pm 1170$ & $6075 \pm 1163$ \\
\hline & $20 \mu \mathrm{g}$ ceruletide & $5708 \pm 792$ & $9539 \pm 1539$ & $11159 \pm 1666$ & $8524 \pm 1235$ & $6748 \pm 800$ \\
\hline
\end{tabular}


Table 3 Threshold and tolerance to electrically induced pain and threshold to thermally induced pain (means $\pm S E M)$ in the 30 minutes before (period 1) and in the four 30 minute periods after drug administration (periods 2 to 5)

\begin{tabular}{|c|c|c|c|c|c|c|}
\hline & \multirow[b]{2}{*}{ Treatment } & \multicolumn{5}{|l|}{ Period } \\
\hline & & 1 & 2 & 3 & 4 & 5 \\
\hline \multirow{4}{*}{$\begin{array}{l}\text { Threshold to electrically } \\
\text { induced pain (milliampère) }\end{array}$} & Placebo & $1 \cdot 08 \pm 0 \cdot 17$ & $1 \cdot 08 \pm 0 \cdot 19$ & $1 \cdot 28 \pm 0 \cdot 26$ & $1 \cdot 32 \pm 0.27$ & $1 \cdot 36 \pm 0 \cdot 28$ \\
\hline & $5 \mu \mathrm{g}$ ceruletide & $1 \cdot(07 \pm 0 \cdot 16$ & $1.43 \pm 0.27$ & $1 \cdot 45 \pm 0 \cdot 28$ & $1.45 \pm 0.26$ & $1 \cdot 43 \pm 0 \cdot 24$ \\
\hline & $10 \mu \mathrm{g}$ ceruletide & $1 \cdot 07 \pm 0 \cdot 14$ & $1 \cdot 36 \pm 0 \cdot 17$ & $1 \cdot 44 \pm 0 \cdot 20$ & $1.47 \pm 0 \cdot 18$ & $1 \cdot 48 \pm 0 \cdot 19$ \\
\hline & $20 \mu \mathrm{g}$ ceruletide & $1 \cdot 16 \pm 0 \cdot 20$ & $1.57 \pm 0.29$ & $1 \cdot 83 \pm 0 \cdot 37$ & $i \cdot 89 \pm 0.41$ & $1.90 \pm 0.38$ \\
\hline \multirow{4}{*}{$\begin{array}{l}\text { Tolerance to electrically } \\
\text { induced pain (milliampère) }\end{array}$} & Placebo & $1.96 \pm 0.25$ & $1.94 \pm 0.32$ & $2 \cdot 23 \pm 0 \cdot 40$ & $2 \cdot 31 \pm 0 \cdot 31$ & $2 \cdot 29 \pm 0 \cdot 32$ \\
\hline & $5 \mu \mathrm{g}$ ceruletide & $1 \cdot 81 \pm 0 \cdot 19$ & $2 \cdot 23 \pm 0 \cdot 31$ & $2 \cdot 28 \pm(0 \cdot 32$ & $2 \cdot 27 \pm 0 \cdot 30$ & $2 \cdot 27 \pm 0 \cdot 29$ \\
\hline & $10 \mu \mathrm{g}$ ceruletide & $1 \cdot 75 \pm 0 \cdot 19$ & $2 \cdot 14 \pm 0 \cdot 25$ & $2 \cdot 19 \pm() \cdot 28$ & $2.23 \pm 0.27$ & $2 \cdot 22 \pm 0 \cdot 27$ \\
\hline & $20 \mu \mathrm{g}$ ceruletide & $1.99 \pm(0.28$ & $2.64 \pm 0.43$ & $2 \cdot 86 \pm 0 \cdot 48$ & $2 \cdot 90 \pm 0 \cdot 50$ & $2 \cdot 96 \pm 0 \cdot 49$ \\
\hline \multirow{4}{*}{$\begin{array}{l}\text { Threshold to thermally } \\
\text { induced pain (milliseconds) }\end{array}$} & Placebo & $1841 \pm 44$ & $1844 \pm 43$ & $1852 \pm 43$ & $1881 \pm 42$ & $1879 \pm 40$ \\
\hline & $5 \mu \mathrm{g}$ ceruletide & $1786 \pm 36$ & $1877 \pm 37$ & $1891 \pm 39$ & $1925 \pm 30$ & $1914 \pm 39$ \\
\hline & $10 \mu \mathrm{g}$ ceruletide & $1742 \pm 3()$ & $1815 \pm 29$ & $1871 \pm 34$ & $1898 \pm 31$ & $1906 \pm 34$ \\
\hline & $20 \mu \mathrm{g}$ ceruletide & $1727 \pm 45$ & $1835 \pm 44$ & $1877 \pm 41$ & $1881 \pm 44$ & $1876 \pm 49$ \\
\hline
\end{tabular}

pain tolerance, $20 \mu \mathrm{g}$ being most effective, while the effects of 5 and $10 \mu \mathrm{g}$ were weaker and nearly identical. Placebo caused only slight changes (Table $3)$. The treatment effects differed significantly $(F(3,168)=16 \cdot 93, p<0 \cdot 001)$. All doses of ceruletide were significantly superior in analgesic efficacy to placebo. $20 \mu \mathrm{g}$ ceruletide being significantly more active than 5 and $10 \mu \mathrm{g}$. Again, there were significant $F$ ratios both for a linear $(\mathrm{F}(1,168)=20 \cdot 83, \mathrm{p}<0 \cdot 001)$ and a quadratic $(F(1,168)=7.02, p<0.01)$ dose response relationship.

\section{THRESHOLD TO THERMALLY INDUCED PAIN}

Ceruletide produced dose related increases of threshold, peak values being attained between 60 and 120 minutes after administration (Table 3 ). The treatment effects differed significantly $(F(3,168)=33.94, p<0 \cdot 001)$. There was a significant linear dose reponse relationship $(F(1,168)=3 \cdot 65$, $p<0.05)$ and all doses of ceruletide were significantly more active than placebo.

\section{REACTION TIME}

Ceruletide produced slight prolongations of reaction time which reached their maximum at 60 minutes after administration, whereas no changes occurred with placebo (mean changes \pm SEM: placebo, $-0.05 \pm 2.42$ milliseconds; $5 \mu \mathrm{g}$ ceruletide. $3.93 \pm 1 \cdot 81$ milliseconds; $10 \mu \mathrm{g}$ ceruletide. $7 \cdot 66 \pm 1.73$ milliseconds; $20 \mu \mathrm{g}$ ceruletide, $8.93 \pm 2 \cdot 13$ milliseconds). The treatment effects differed significantly $(\mathrm{F}(1,168)=3 \cdot 16, \mathrm{p}<0 \cdot 1)$. Twenty and $10 \mu \mathrm{g}$ but not $5 \mu \mathrm{g}$ ceruletide were significantly more active than placebo.

SELF-RATINGS

Self-ratings of well-being decreased with all doses of ceruletide, the maximum effect being reached between 60 and 90 minutes after administration. The treatment effects differed significantly $(F(3.168)=8 \cdot 66, p<0.005)$, whereas the changes induced by the three doses of ceruletide did not differ from each other.

Self-ratings of activation and of warmth were not influenced systematically by any one dose of ceruletide.

\section{SIDE EFFECTS}

Ceruletide caused only mild side effects. Tiredness was reported by one subject after each 5 and $20 \mu \mathrm{g}$ ceruletide and by four subjects after $10 \mu \mathrm{g}$. Two subjects reported abdominal discomfort after $20 \mu \mathrm{g}$ ceruletide and one subject each after the other treatments. With $20 \mu \mathrm{g}$ ceruletide, two subjects complained of mild sickness and two others of dizziness. Headache was reported twice after $10 \mu \mathrm{g}$ ceruletide and once after each 5 and $20 \mu \mathrm{g}$. Five, six, and eight subjects complained of pain at the injection site after administration of 5.10 and $20 \mu \mathrm{g}$ ceruletide, respectively.

\section{Discussion}

The results of the present study show that ceruletide dose dependently increased jejunal motor activity of the phase II type (intermittent activity) and decreased activity of the phase I type (quiescence) of the MMC. The occurrence but not the duration of activity fronts (phase III) decreased with increasing dose of ceruletide. As to the intervals between activity fronts, no information can be drawn from the present data, as the recording time was relatively short. Irrespective of the various phases of the MMC, ceruletide increased dose dependently the number and the mean amplitude of jejunal contrac- 
tions and also increased the area under pressure curve - that is, overall motor activity. Thus, ceruletide elicited a contractile pattern which resembled postprandial activity. These findings are in accordance with results from animal studies, in which similar results were found with both ceruletide $^{731}$ and cholecystokinin. ${ }^{24}{ }^{32}$ There is no unanimity as to the functional significance of the motility pattern induced by these peptides. It seems, however, that both mixing and propulsion of small intestinal contents are enhanced, ${ }^{6}{ }^{31}$ as the main part of propulsion occurs during phase II. ${ }^{33}$ The doses in which ceruletide acts on the jejunum are about in the same range as the doses of ceruletide and of cholecystokinin eliciting cholecystokinetic and pancreozyminic actions and inhibiting gastric emptying, all of which are considered to be physiological actions of cholecystokinin. ${ }^{34} 35$

Ceruletide also produced dose dependent effects on threshold and tolerance to electrically induced pain and on threshold to thermally induced pain. These actions lasted longer - that is, until the end of the 120 minute period after drug administration, than the effects on the jejunum. The analgesia produced by 5 and $10 \mu \mathrm{g}$ ceruletide was of similar magnitude to that produced by intravenous doses of 4.2 and $8.4 \mu \mathrm{g} / \mathrm{h} / 70 \mathrm{~kg}$ body weight in an earlier investigation ${ }^{2122}$. Twenty micrograms ceruletide was significantly superior in analgesic efficacy to both 5 and $10 \mu \mathrm{g}$ of the peptide and yielded effects comparable with those produced by $28 \mathrm{mg} / \mathrm{h} / 70 \mathrm{~kg}$ body weight pentazocine intravenously in the above mentioned study. ${ }^{22}$ In parallel to earlier investigations, ${ }^{21} 2236$ ceruletide caused only mild sedative and other side effects. With all doses of the peptide, however, the subjects reported less well being on self rating scales than with placebo. The mechanism by which ceruletide produces analgesia remains to be clarified. A direct central effect seems unlikely, as peripherally administered ceruletide or cholecystokinin do not readily pass the blood brain barrier ${ }^{37-40}$ The fact that cholecystokinin is present in primary sensory neurones, ${ }^{41}$ in vagal afferent fibres, ${ }^{42}$ and in splanchnic and somatic peripheral nerves ${ }^{42}{ }^{43}$ suggests that it acts as an active neurotransmitter in these locations and thus may play a role in the processing of sensory and nociceptive information.

It is concluded that ceruletide, in healthy man, stimulates fasting jejunal motor activity and increases threshold and tolerance to experimentally induced pain significantly and in a dose dependent fashion. Although it can not be assumed that the same stimulatory effects on jejunal motor activity will occur also in patients suffering from postoperative hypomotility, the present results, together with results from clinical studies, ${ }^{6-10}$ seem to indicate the need for a further investigation of the potentially beneficial effects of ceruletide in the postoperative phase, where intestinal atonia as well as pain pose serious therapeutic problems.

\section{References}

1 Anastasi A, Erspamer V, Endean R. Isolation and amino acid sequence of caerulein, the active decapeptide of the skin of Hyla caerulea. Arch Biochem 1968; 125: 57-68.

2 Bernardi L, Bosisio G, de Castiglione R, Goffredo O. Synthesis of caerulein. Experientia 1967; 23: 700-1.

3 Bertaccini G, Agosti A. Action of caerulein on intestinal motility in man. Gastroenterology 1971; 60: 55-63.

4 Labò G, Barbara L, Lanfranchi GA, Bortolotti M, Miglioli M. Modification of the electrical activity of the human intestine after serotonin and caerulein. $\mathrm{Am} \mathrm{J}$ Dig Dis 1972; 17: 363-72.

5 Scott LD, Summers RW. Effect of glucagon and caerulein on propulsion and motility in the rat small intestine. Gastroenterology 1974; 66: 774.

6 Bertaccini G. Action of caerulein on gastrointestinal motility in healthy subjects and patients: in vivo and in vitro studies. Rendic Rom Gastroenterol 1971; 3: 122.

7 Agosti A, Bertaccini G, Paulucci R, Zanella E. Caerulein treatment for paralytic ileus. Lancet 1971; 1: 395.

8 Haas W, Rueff FL. Caerulein in der Therapie der postoperativen Darmatonie und des Ileus. Therapiewoche 1978; 28: 8939-44.

9 Montero VF, Laganga AM, Garcia EA. Usefulness of caerulein in the treatment of post-operative intestinal atony. J Int Med Res 1980; 8: 98-104.

10 Madsen PV, Lykkegaard-Nielsen M, Nielsen OV. Ceruletide reduces post-operative intestinal paralysis. A double-blind placebo-controlled trial. Dis Colon Rectum 1983; 26: 159-60.

11 Gutiérrez JG, Chey WY, Dinoso VP. Actions of cholecystokinin and secretin on the motor activity of the small intestine in man. Gastroenterology 1974; 67: $35-41$.

12 Dollinger HC, Berz R, Raptis S, Uexküll T von, Goebell H. Effects of secretin and cholecystokinin on motor activity of human jejunum. Digestion 1975; 12: 9-16.

13 Fleckenstein P, Öigaard A. Effects of cholecystokinin on the motility of the distal duodenum and the proximal jejunum in man. Scand J Gastroenterol 1977; 12: $375-8$.

14 Wingate DL, Pearce EA, Hutton $M$, Dand $A$, Thompson $\mathrm{HH}$, Wünsch E. Quantitative comparison of the effects of cholecystokinin, secretin, and pentagastrin on gastrointestinal myoelectric activity in the conscious fasted dog. Gut 1978; 19: 593-601.

15 Jurna I, Zetler G. Analgesia following central adminis- 
tration of caerulein and cholecystokinin octapeptide (CCK-8). Naunyn Schmiedebergs Arch Pharmacol 1980; 13 (suppl): R26.

16 Zetler G. Analgesia and ptosis caused by caerulein and cholecystokinin octapeptide (CCK-8). Neuropharmacology 1980; 19: 415-22.

17 Basso N, Bagarani M, Gizzonio D et al. Analgesic effect of ceruletide (CRL) in biliary and renal colic. Gastroenterology 1981; 80: 1105.

18 Basso N, Materia A, Fiocca M et al. Treatment of biliary colic with ceruletide. Gastroenterology 1980; 78: 1137.

19 Santamaria A, Lucani G, Montorsi M. Praga C. Action de la céruléine sur la colique hépatique. Nouv Presse Méd 1979; 8: 2482.

20 Piazza E, Brambilla M, Cattaneo MT, Martini A, Pacciarini MA. Analgesic activity of ceruletide in cancer patients. In: Basso N, Lezoche E, Speranza V, Walsh JH, eds. International symposium on brain-gut axis: the new frontier. Florence, June 29/30 - July 1, 1981 [Abstracts]. Florence, 1981: 146.

21 Stacher G, Schmierer G, Steinringer H, Schneider C, Winklehner $\mathrm{S}$. Ceruletide alleviates experimentally induced pain. Regul Pept 1983; suppl 2: S109.

22 Stacher G, Steinringer H, Schmierer G, Winklehner S. Schneider C. Ceruletide increases threshold and tolerance to experimentally induced pain in healthy man. Peptides 1982; 3: 955-62.

23 Code CF, Marlett JA. The interdigestive myo-electric complex of the stomach and small bowel of dogs. J Physiol (Lond) 1975; 246: 289-309.

24 Vantrappen G, Janssens J, Hellemans J, Ghoos Y. The interdigestive motor complex of normal subjects and patients with bacterial overgrowth of the small intestine. J Clin Invest 1977; 59: 1158-66.

25 Lahoda R, Stacher G, Bauer P. Experimentally induced pain: measurement of pain threshold and pain tolerance using a new apparatus for electrical stimulation of the skin. Int J Clin Pharmacol 1977; 15: 51-6.

26 Stacher G, Bauer P, Ehn I, Schreiber E. Effects of tolmetin, paracetamol, and of two combinations of tolmetin and paracetamol as compared to placebo on experimentally induced pain. A double blind study. Int $J$ Clin Pharmacol 1979; 17: 250-5

27 Stacher G, Bauer P, Schneider C, Winklehner S, Schmierer G. Effects of a combination of naproxen sodium and codein per os on experimentally induced pain. Eur J Clin Pharmacol 1982; 21: 485-90.

28 Wohlzogen FX, Weish P. Vergleichende Analgetikaprüfung unter Verwendung der Schmerzschwellenzeit bei thermischer Hautreizung als Kriterium für die analgetische Wirkung. Wien Klin Wochenschr 1969; 81: 616-8.
29 Games PA. Computer programs for robust analyses in multifactor analysis of variance designs. Educ Psychol Measure 1975; 35: 147-52.

30 Holme S. A simple sequentially rejective multiple test procedure. Scand J Stat 1979; 6: 65-70.

31 Scott LD, Summers RW. Correlation of contractions and transit in rat small intestine. Am J Physiol 1976; 230: $132-7$.

32 Mukhopadhyay AK, Thor PJ, Copeland EM, Johnson LR, Weisbrodt NW. Effect of cholecystokinin on myoelectric activity of small bowel of the dog. Am J Physiol 1977; 232: E44-7.

33 Bueno L. Fioramonti J, Ruckebusch Y. Rate of flow of digesta and electrical activity of the small intestine in dogs and sheep. J Physiol (Lond) 1975; 249: 69-85.

34 Debas HT, Farooq O, Grossman MI. Inhibition of gastric emptying is a physiological action of cholecystokinin. Gastroenterology 1975; 68: 1211-7.

35 Valenzuela JE, Grossman MI. Effect of pentagastrin and caerulein on intragastric pressure in the dog. Gastroenterology 1975; 69: 1383-4.

36 Stacher G, Steinringer G, Schmierer G, Schneider C, Winklehner $S$. Ceruletide decreases food intake in non-obese man. Peptides 1982; 3: 607-12.

37 Cornford EM, Braun LD, Crane PD. Oldendorf WH. Blood-brain barrier restriction of peptides and the lower uptake of enkephalin. Endocrinology 1978; 103: 1297-303.

38 Kruse-Larsen C, Rehfeld JF. Gastrin in human cerebrospinal fluid: lack of correlation with serum concentrations. Brain Res 1979; 176: 189-91.

39 Debas H, Yamada T, Oldendorf W, Passaro E Jr. The permeability of blood-brain and brain-blood barrier to the octapeptide of CCK. In: Basso N, Lezoche E, Speranza V. Walsh JH, eds. International symposium on brain-gut axis: the new frontier, Florence, June 29/30 - July 1, 1981 [Abstracts]. Florence, 1981: 47.

40 Zhu XG, Lewis BG, Lilja P, Greely G, Thompson JC. Effects of cholecystokinin and bombesin on concentrations of cholecystokinin in plasma and cerebral spinal fluid in dogs. Gastroenterology 1982; 82: 1218.

41 Larsson LI, Rehfeld JF. Localization and molecular heterogeneity of cholecystokinin in the central and peripheral nervous system. Brain Res 1979; 165: 201-18.

42 Dockray GJ, Gregory RA, Tracy HJ, Zhu WY. Transport of cholecystokinin-octapeptide-like immunoreactivity toward the gut in afferent vagal fibers in cat and dog. J Physiol (Lond) 1981; 314: 501-11.

43 Rehfeld JF, Larsson LI, Goltermann NR et al. Neural regulation of pancreatic hormone secretion by the C-terminal tetrapeptide of CCK. Nature 1980; 284: 33-8. 